\title{
Texture and eco-piezoceramics
}

\section{E. Fuentes-Cobas ${ }^{1}$, J. R. Narváez-Monroy ${ }^{1}$, A. Campos-Rodríguez ${ }^{1}$, M. E. Montero-Cabrera', R. Domínguez- García $^{1}$, E. E. Villalobos-Portillo², L. Fuentes-Montero ${ }^{3}$, B. Batista-Fierro ${ }^{4}$, M. S. Luévano-Jáquez ${ }^{4}$, L. Pardo ${ }^{5}$}

${ }^{1}$ Centro de Investigación en Materiales Avanzados, Chih., México, ${ }^{2}$ European Synchrotron Radiation Facility, Grenoble, France, ${ }^{3}$ Diamond Light Source, Didcot, UK, ${ }^{4}$ Universidad Autónoma de Chihuahua, Chih., México, ${ }^{5}$ Instituto de Ciencia de Materiales de Madrid, Madrid, Spain

\section{luis.fuentes@cimav.edu.mx}

Research on lead-free piezoceramics is a trending topic [1]. A significant component of this search is the characterization of the effect of texture on the properties of polycrystalline electroceramics. The present contribution describes an integrated methodology, systematized in a software package, to solve the following tasks: (a) interpretation by numerical simulation of XRD patterns produced by textured samples; (b) forecast of the effective elasto-electrical properties of piezoceramics, starting from the knowledge of the corresponding single-crystal tensors and the texture determined in (a).

Part (a) considers 1D and 2D diffraction experiments, with Bragg-Brentano, grazing incidence and transmission geometries. The inverse pole figure of the symmetry axis of fiber-textured piezoceramics is proposed and refined by a Rietveld-type procedure [2].

The calculations in part (b) are performed using a variant of the Voigt-Reuss-Hill approximations. Particular precautions are taken with regard to the selection of the quantities considered as independent variables [3].

The computer programs developed to solve the proposed tasks are shown, the use of the MPOD database [4] in this type of work is described, and representative case studies are presented.

Fig. 1 shows as an example the computerized modelling of the variation of the representative longitudinal surfaces of the elastic compliance $s(\mathbf{h})$ and the charge constant $d(\mathbf{h})$ of the lead-free piezoceramic $0.95\left(\mathrm{Na}_{0.5} \mathrm{Bi}_{0.5}\right) \mathrm{TiO}_{3}-0.05 \mathrm{BaTiO}_{3}(\mathrm{BNBT} 5)$ as the texture evolves from relatively sharp to a random distribution.
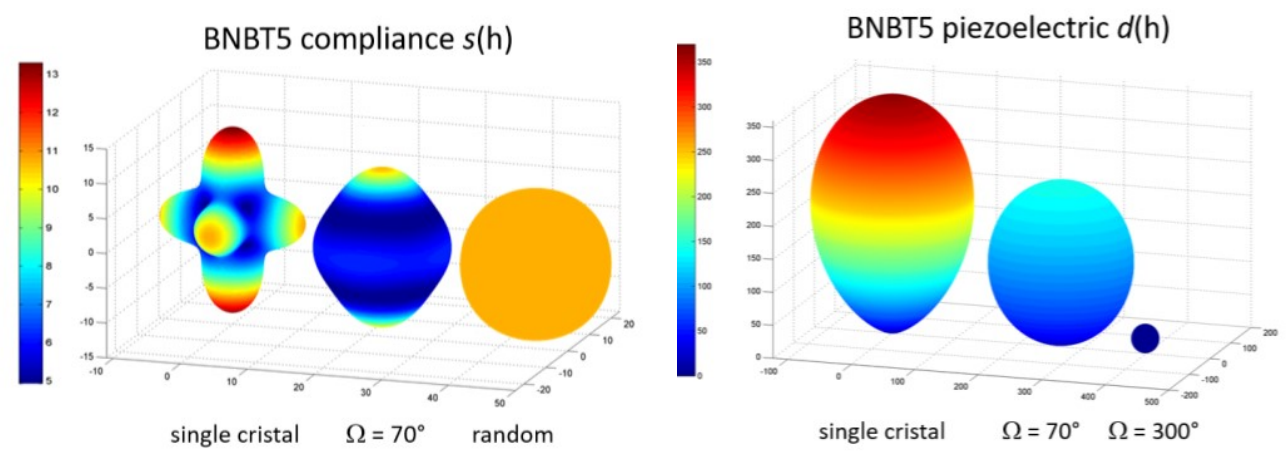

Figure 1. Modelled effect of axial texture on elastic compliance and piezoelectric charge constant of lead-free BNBT5 piezoceramic. As the width of the orientation distribution $(\Omega)$ increases, the elasticity tends to isotropic and the piezoelectricity collapses to zero.

[1] Villafuerte-Castrejón, M. E., Morán, E., Reyes-Montero, A., Vivar-Ocampo, R., Peña-Jiménez, J. A., Rea-López, S. O., \& Pardo, L. (2016). Materials 9, 21.

[2] Burciaga-Valencia, D. C., Villalobos-Portillo, E. E., Marín-Romero, J. A., Del Río, M. S., Montero-Cabrera, M. E., Fuentes-Cobas, L.E. \& Fuentes-Montero, L. (2018). J. Mater. Sci: Mater. Electron. 29, 15376.

[3] Villalobos-Portillo, E. E., Fuentes-Montero, L., Montero-Cabrera, M. E., Burciaga-Valencia, D. C. \& Fuentes-Cobas, L. E. (2019). Mater. Res. Express 6, 115705.

[4] Fuentes-Cobas, L. E., Chateigner, D., Fuentes-Montero, M. E., Pepponi, G \& Grazulis, S. (2017). Adv. Appl. Ceram. $116,428$.

\section{Keywords: texture; lead-free piezoceramics; diffraction modelling; Voigt-Reuss-Hill approximation}

Sponsorship by the Consejo Nacional de Ciencia y Tecnología (México), Projects 257912 and 270738, is appreciated. Support from the Project MAT2017-86168-R "Piezocerámicas ecológicas para la generación de ultra-sonidos" (CSIC, Spain), is acknowledged. 